\title{
Effects of oestrone and progesterone on collagen and ascorbic acid content in the endometrium and myometrium of the rat
}

\author{
J. M. Yochim and D. G. Blahna \\ Department of Physiology and Cell Biology, University of Kansas, \\ Lawrence, Kansas 66045, U.S.A.
}

\begin{abstract}
Although endometrial progestational differentiation appears to be regulated precisely by ovarian steroid hormones (Yochim \& DeFeo, 1963), little evidence is available concerning the hormonal effects on uterine collagen during the preimplantation stages of progestation. The present study was undertaken to examine the effects of oestrone and progesterone on endometrial and myometrial collagen content in the rat during the oestrous cycle and early pseudopregnancy. Hydroxyproline content was used as an index of extractable collagen, and ascorbic acid was also measured, since this vitamin has been implicated in the hydroxylation of proline during collagen production (Gould, 1958).

Adult female Holtzman rats $(200-300 \mathrm{~g})$ were caged individually in temperature $\left(23 \pm 1^{\circ} \mathrm{C}\right)$ - and light-controlled ( $14 \mathrm{hr}$ light/24 hr) quarters. Animals were allowed unrestricted access to food and water, and vaginal smears for each rat were recorded daily for at least 2 or 3 cycles before use. Pseudopregnancy was induced by mechanical stimulation of the cervix during pro-oestrus and oestrus. The last day of vaginal cornification was designated Day 0 of pseudopregnancy and the first day of vaginal leucocytic infiltration was Day 1. Ovariectomy was performed at 09.00-12.00 hours on Day 0 under ether anaesthesia, and at this time $1.0 \mu \mathrm{g}$ oestrone, $2.0 \mathrm{mg}$ progesterone, or the combination of these steroids was injected s.c. in $0.1 \mathrm{ml}$ sesame oil each day. These hormone doses have been shown to maintain uterine sensitivity to decidualization in a manner similar to that in intact pseudopregnant animals (Yochim \& DeFeo, 1962, 1963). The treatment is also consistent with what is known about ovarian steroid secretory activity during early pregnancy in the rat (Butcher, Collins \& Fugo, 1975).
\end{abstract}

The rats were weighed and killed by cervical dislocation at the times shown (Table 1). The uteri were quickly removed, placed on an ice-cold glass plate, and each horn was trimmed of adhering fat and mesentery, blotted, and weighed to the nearest $0.1 \mathrm{mg}$ on a torsion balance. The uterine horns were split longitudinally, the epithelium and subepithelial endometrial stroma were scraped gently from each horn, combined, weighed and recorded as total uterine endometrium. Endometrial scrapings (5-25 mg) and sections of 'myometrium (10-30 mg) were then analysed for hydroxyproline (Woessner, 1961) or ascorbic acid (Maickel, 1960), using different groups of animals for the two assays.

Changes in uterine hydroxyproline and ascorbic acid content during the oestrous cycle and the first 6 days of pseudopregnancy are shown in Table 1. During the cycle, endometrial hydroxyproline content was highest on the day of pro-oestrus, and lowest during metoestrus. The highest hydroxyproline content during pseudopregnancy (Day 4$)$ was significantly less $(P<0.01)$ than that measured during pro-oestrus. The ascorbic acid changes were similar to those measured for hydroxyproline with the exception of a significant decline in content $(P<0.01)$ between Days 4 and 6 of pseudopregnancy.

By contrast, in the myometrium, hydroxyproline content varied little during the oestrous cycle and remained stable but at a lower level throughout early pseudopregnancy. The ascorbic acid content of the myometrium fluctuated cyclically with a peak during pro-oestrus and a trough during metoestrus, but changed little during pseudopregnancy.

Ovariectomy on Day 0 prevented the rise in endometrial hydroxyproline content found in intact animals 4 days later (Table 1). The values were similar to those measured in intact rats on Day 1 . Oestrone treatment had no effect and the pattern during the 4 days (data not shown) was similar to 


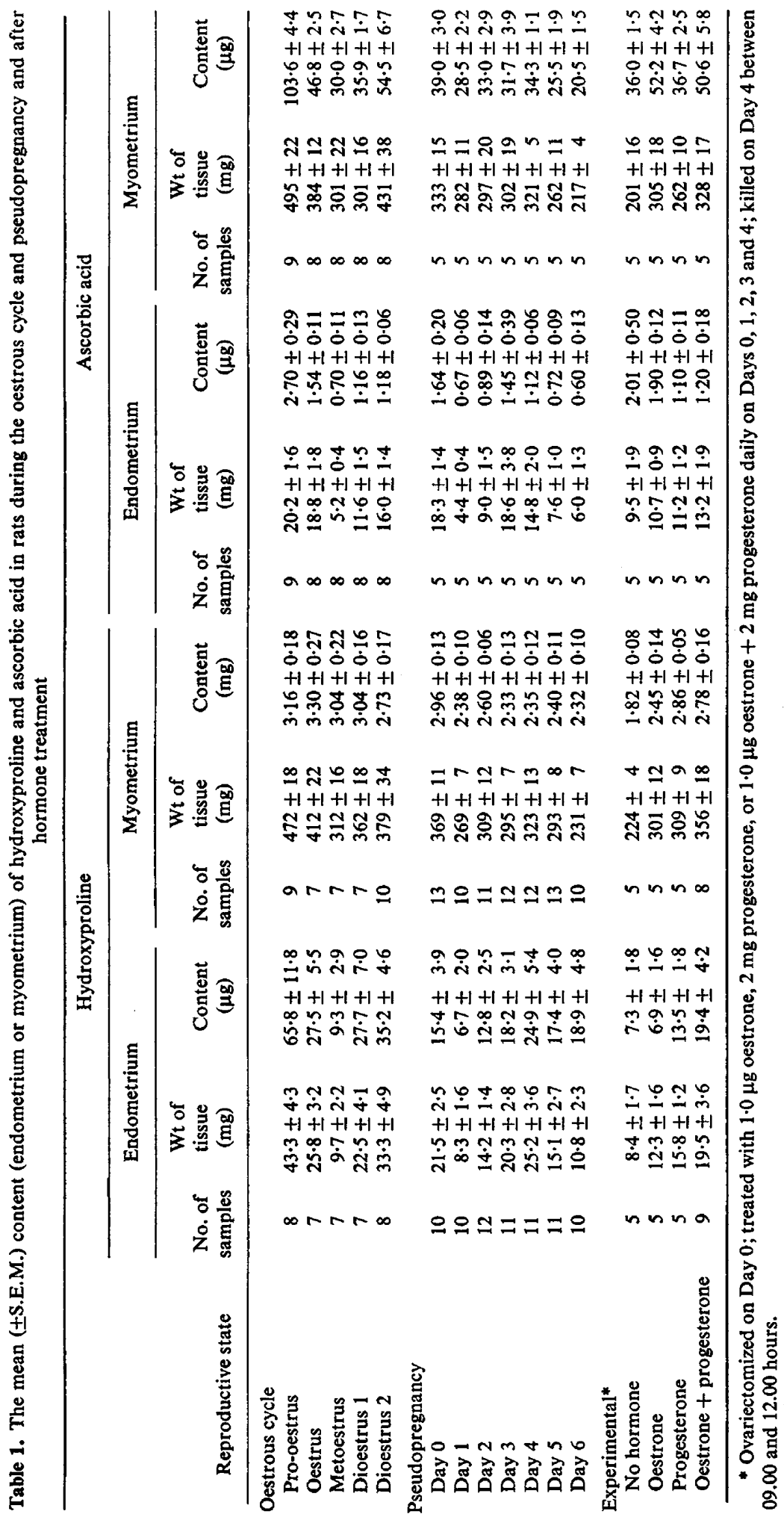


that in ovariectomized controls. Daily injection of progesterone, however, caused a significant rise $(P<0.05)$ in hydroxyproline content by Day 4 , a response which was maintained, perhaps enhanced, when oestrogen was also given. The pattern during the first 4 days of this treatment (data not shown) was similar to that in intact rats. By contrast, ascorbic acid content in the endometrium did not change substantially after ovariectomy. Replacement therapy with oestrone, progesterone, or the combination of hormones caused no dramatic changes in ascorbic acid content, when compared with ovariectomized controls on Day 4. Similar, though not identical, changes were found in the myometrium after ovariectomy and steroid hormone replacement.

The present experiments indicate that dramatic fluctuations in collagen content occur in the endometrium but not in the myometrium of the rat. Endometrial collagen was extremely sensitive to changes in the hormonal state of the animal in the cycle and early pseudopregnancy, but myometrial collagen did not appear to respond to hormone changes. These results are in contrast to those of earlier workers (Harkness, Harkness \& Moralee, 1957; Smith \& Kaltreider, 1963; Morgan, 1963; Kao, Hitt, Bush \& McGavack, 1964) and may be due to the separation of endometrium from myometrium in the present experiments.

The absence of the ovaries prevented the rise in endometrial collagen content that was found during the first 4 days of pseudopregnancy (Table 1), but replacement with progesterone or oestrogen + progesterone caused an increase in collagen content to a level similar to that measured in intact rats on Day 4 of pseudopregnancy. Daily low doses of oestrogen were without effect, indicating that the rise in collagen content during early pseudopregnancy is probably not the result of influence by oestrogenic hormones, since higher dosages of oestrogen would have impaired progestation (Yochim \& DeFeo, 1963).

Jeffrey, Coffey \& Eisen (1971) noted that progesterone, either alone or in combination with oestrogen, when added to cultures of post-partum rat uteri suppressed collagenase activity and reduced collagen catabolism significantly. If this is a major action of progesterone, it is possible that the gradual build-up of collagen content in endometrium during the first 4 days of pseudopregnancy in the present experiments is the result of a low level of synthesis (induced or maintained by low levels of oestrogen) coupled with a suppression of collagenase activity by progesterone. The gradual rise in hydroxyproline content during this time in intact or in hormone-treated rats (Table 1) might be a reflection of such an action.

This investigation was supported by grant No. HD-05090 from the National Institute of Child Health and Human Development, and by a Public Health Service Research Career Development Award (K4-HD-8558) to J.M.Y. from NICHHD.

\section{References}

Butcher, R.L., Collins, W.E. \& Fugo, N.W. (1975) Altered secretion of gonadotropins and steroids resulting from delayed ovulation in the rat. Endocrinology 96, 576-586.

GouLd, B.S. (1958) Biosynthesis of collagen. III. The direct action of ascorbic acid on hydroxyproline and collagen formation in subcutaneous polyvinyl sponge implants in guinea pigs. J. biol. Chem. 232, 637649.

Harkness, M.L.R., Harkness, R.D. \& Moralee, B.E. (1957) The effect of the oestrous cycle and of hormones on the collagen content of the uterus of the rat. J. Physiol., Lond. 135, 270-280.

Jefrrey, J., Coffey, R.J. \& EiSeN, A.Z. (1971) Studies on uterine collagenase in tissue culture. II. Effect of steroid hormones on enzyme production. Biochim. biophys. Acta 252, 143-149.

KaO, K.Y.T., HitT, W.E., BUSH, A.T. \& McGaVaCK, T.H. (1964) Connective tissue. XI. Factors affecting collagen synthesis by rat uterine slices. Proc. Soc. exp. Biol. Med. 115, 422-424.

Maickel, R.P. (1960) A rapid procedure for the determination of adrenal ascorbic acid. Application of the Sullivan and Clarke method to tissue. Analyt. Biochem. 1, 498-501.

Morgan, C.F. (1963) Temporal variations in the collagen, noncollagen protein and hexosamine of the uterus and vagina. Proc. Soc. exp. Biol. Med. 112, 690-694.

Smith, O.W. \& Kaltreider, N.B. (1963) Collagen content of the nonpregnant rat uterus as related to the functional responses to estrogen and progesterone. Endocrinology 73, 619-628.

WOESSNER, J.F., JR (1961) The determination of hydroxyproline in tissue and protein samples containing small proportions of this imino acid. Archs Biochem. Biophys. 93, 440-447.

Yoснім, J.M. \& DeFeo, V.J. (1962) Control of decidual 
growth in the rat by steroid hormones of the ovary. Endocrinology 71, 134-142.

Yochim, J.M. \& DeFeo, V.J. (1963) Hormonal control of the onset, magnitude and duration of uterine sensitivity in the rat by steroid hormones of the ovary. Endocrinology 72, 317-326.

Received 1 July 1975 